Online Journal of Biological Sciences 6 (1): 1-13, 2006

ISSN 1608-4217

(c) 2006 Science Publications

\title{
Review of Prodigiosin, Pigmentation in Serratia marcescens
}

\author{
${ }^{1}$ Anita Khanafari, ${ }^{1,2}$ Mahnaz Mazaheri Assadi and ${ }^{1}$ Fatemeh Ahmadi Fakhr \\ ${ }^{1}$ Department of Microbiological Sciences, Islamic Azad University, 4th Floor, North of Tehran, Darband Str. \\ Qods Sqr., Tajrish Sqr. Tehran, Iran \\ ${ }^{2}$ Department of Forest Sciences, Faculty of Forestry, The University of British Columbia, 4th Floor \\ Forest Sciences Centre \# 4320-2424 Main Mall Vancouver, British Columbia Canada V6T 1Z4
}

\begin{abstract}
Prodigiosins, a family of natural red pigments characterized by a common pyrrolylpyrromethane skeleton, are produced by various bacteria that first characterized from Serratia marcescens. This pigment is a promising drug owing to its reported characteristics of having antifungal, immunosuppressive and anti-proliferative activity. From an industrial point of view to obtain optimal conditions to enhance the growth of Serratia marcescens and the pigment production is necessity. In present study, the production condition, physicochemical and functional characteristics, structure, genetic and gene expression, apoptosis and toxigenic effects of prodigiosin will be discussed in-order to contribute to the world of Serratia marcescens with respect to its prodigiosin production property.
\end{abstract}

Keywords: Prodigiosin production, Serratia marcescens, antifungal, apoptosis, anti-cancer effect

\section{INTRODUCTION}

Serratia spp are gram negative bacteria, classified in the large family of Enterobacteriaceae. Serratia spp can be distinguished from other genera by its production of three special enzymes DNAase, lipase and gelatinase ${ }^{[1]}$. However, a number of other traits have been identified that may contribute to pathogenesis. These include swimming and swarming motility and extracellular enzyme activities, i.e. nuclease, protease and haemolysin ${ }^{[2]}$. Serratia spp occur in water and soil, on plant, in insects and in man and animal ${ }^{[3]}$. S. marcescens is the only pathogenic species, although rare reports of infection with S. plymuthica, liquefaciens, rubidaea and odifera exist. Since the early 1900 's, physicians have used S. marcescens to study transmission of microorganisms, as it was assumed to be a harmless saprophyte. In the hospital, Serratia tends to colonize the respiratory and urinary tracts of adults, rather than the GI tract. Serratia sp is responsible for $1.4 \%$ of nosocomial septicemia. It is also responsible for $2 \%$ of lower respiratory, urinary tract and surgical wound infections. Serratia sp can be a cause of meningitis, especially after surgical intervention. Also reported is endocarditis and osteomyelitis in heroin addicts. Crude mortality for Serratia septicemia is $26 \%$, while the mortality for meningitis and endocarditis is very $\operatorname{high}^{[4]}$. S. marcescens and S. liquefaciens may cause lethal septicaemia in insects ${ }^{[3]}$. Another characteristic feature of the Serratia among the Klebsiellaea is the production of cell associated red color pigment called prodigiosin. Serratia marcescens isolated from infected adults generally does not synthesize prodigiosin ${ }^{[3,5,6]}$. However, pigmentation is only present in a small percentage of isolated cultures only under aerobic condition. Pigment production is highly variable among species and is dependence on many factors such as species type and incubation time. On some media Rugamonas rubra produces so much prodigiosin that, as the $\mathrm{pH}$ drops, it precipitates out within the cells and colonies change from pillar box red to deep maroon, often with a green metallic sheen under reflected light. At this stage most organisms in the colony are no longer viable ${ }^{[7]}$. In presence of $\mathrm{Fe}^{2+}$, some strains of Serratia marcescens produce a water-soluble pink pigment pyrimine, L-2-(2-pyridyl-D'-pyrroline-5carboxylic acid), which diffuses into the agar surrounding the colonies ${ }^{[3]}$. Serratia marcescens secretes a variety of extracellular enzymes including chitinase $^{[8]}$. S. marcescens is one of the most effective bacteria for degradation of chitin ${ }^{[9]}$. When this bacterium is cultivated in the presence of chitin, a variety of chitinolytic enzymes and chitin-binding proteins can be detected ${ }^{[10-11]}$.S marcescens produces at least three chitinases (ChiA, ChiB and ChiC), a chitobiase and a putative chitin-binding protein $(\mathrm{CBP} 21)^{[10,12-14]}$. It is conceivable, but not certain, that these five proteins represent the complete chitinolytic machinery of the bacterium. The chitinolytic machinery of $S$. marcescens is of great interest because it is one of the best characterized chitinolytic machineries known to date ${ }^{[15]}$. A synergistic inhibitory activity of prodigiosin and chitinolytic enzymes was observed against spore germination of Botrytis cinerea $^{[16]}$,

Corresponding Author: Anita Khanafari, Department of Microbiological Sciences, Islamic Azad University, 4th Floor, North of Tehran, Darband Str., Qods Sqr., Tajrish Sqr. Tehran, Iran, Tel: +98(21)22082141, Fax: +98-(21) 22700103 
selective activity against cancer cell lines ${ }^{[17]}$, enhanced lethal and inhibitory activity of Cry1C BT toxin along with prodigiosin ${ }^{[3]}$ and the lipase of Serratia sp used for the manufacture of an intermediate of diltiazem a vasodilator ${ }^{[18]}$ is well studied. Pryce \& Terry ${ }^{[19]}$ in their unpublished observation have reported on the possibility of a membrane permeable positive prodigiosin regulator synthesized by Serratia marcescens. Optimum growth of all strains of Serratia has been observed at $\mathrm{pH} 9$ and at temperatures from 20$37^{\circ} \mathrm{C}^{[1]}$.

In the present review, the diversity of prodigiosin, their production conditions in laboratory, structure, biosynthesis and the inhibitory factors for prodigiosin production, gene expression and apoptosis, toxigenic and anti-cancer effects of this pigment are discussed.

\section{Prodigiosin production conditions (media,} temperature and carbon source): Serratia spp, like other Enterobacteriaceae, grow well on ordinary media under anaerobic and aerobic conditions. They grow well on synthetic media using various compounds as a single carbon source. Many types of differential and selective media have been developed for the isolation and presumptive testing of Serratia sp. Capryllate Thallous [CT] agar contains caprylate as a carbon source for Serratia sp and thallous salts as inhibitors for other organisms ${ }^{[20]}$ and $\mathrm{CT}$ is the best at selecting for Serratia sp. The regular liquid media currently being used for prodigiosin biosynthesis are nutrient broth ${ }^{[19]}$, peptone glycerol broth ${ }^{[18]}$ and production medium ${ }^{[21}$ etc. According to the medium patented by Nakamura ${ }^{[22}$ the author has used sodium oleate $2 \%$ and has also studied oleic acid substitution instead of sodium oleate and has used only triolein as substrate and reported a yield of $0.69 \mathrm{mg} \mathrm{mL}^{-1}$ prodigiosin. Having an insight on the composition of already published media the idea of designing a new, nutritious and economically cheap medium was thought of for the prodigiosin biosynthesis. Initial comparative work was done using powdered sesame seed in water, nutrient broth and peptone glycerol broth as a growth medium for Serratia marcescens. After having observed sesame seed to give a better yield in terms of prodigiosin biosynthesis further comparision was done with readily available cheaper sources like peanut and coconut. Sesame oil, peanut oil and coconut oil were also compared with the rest of the media. The media were also compared for growth at three different temperatures in terms of prodigiosin production. This work lead to the observation that fatty acids as the substrate supported enhanced prodigiosin production the various components in the seeds as substrate could have stimulated cell density which in turn could have resulted in higher accumulation of the positive regulator inside the cell there by triggering excessive pigment production. The powdered peanut seed medium supported the prodigiosin biosynthesis even at $37^{\circ} \mathrm{C}$ which was not so in the case of nutrient or peptone glycerol broth with and without sugars ${ }^{[1]}$. As indicated from Table 1 the crushed sesame seed broth gave the maximum yield of prodigiosin at $28^{\circ} \mathrm{C}, 30^{\circ} \mathrm{C}$ and $37^{\circ} \mathrm{C}$ when compared to nutrient broth and peptone glycerol broth. The maximum prodigiosin production was seen at $28^{\circ} \mathrm{C}$ and $30^{\circ} \mathrm{C}$ in nutrient broth. At $37^{\circ} \mathrm{C}$ Serratia marcescens did not show any pigment production in nutrient broth and the culture broth was white in color. In case of the powdered peanut broth, even at $37^{\circ} \mathrm{C}$, pigment production was observed and in fact it was equal to the amount of pigment production seen in nutrient broth at $30^{\circ} \mathrm{C}$. In case of peanut broth only after second generation growth of Serratia marcescens at $42^{\circ} \mathrm{C}$, there was complete block of pigment production ${ }^{[1]}$. Reversion of the $42^{\circ} \mathrm{C}$ grown white culture of Serratia marcescens which had shown pigment block in powdered peanut broth, showed the re-synthesis of pigment production when incubated at $28^{\circ} \mathrm{C}$. Reversion experiment was done to confirm that at $42^{\circ} \mathrm{C}$ the culture was still viable and only the pigment production was blocked ${ }^{[1]}$. In the bioreactor study with an internal adsorbent for prodigiosin the final yield was $13 \mathrm{mg} \mathrm{mL}^{-1[21]}$ and the media used had dextrose in the culture broth and casein in production medium. Chang et al., ${ }^{[23]}$ have quoted a medium containing ethanol and carbon source but the yield was $3 \mathrm{mg} \mathrm{mL}^{-1}$. Nakamura ${ }^{[22]}$ in his patent describes the use of sodium oleate media and the substitution of sodium oleate with oleic acid. Addition of maltose to nutrient broth enhanced pigment production only by 2 fold as at $28^{\circ} \mathrm{C}$ and $30^{\circ} \mathrm{C}$ as shown in Table 1 . Nutrient broth with glucose showed a two fold increase at $28^{\circ} \mathrm{C}$. The pigment production was more in sesame seed broth even without the addition of any sugars, when compared to sesame seed broth with glucose or maltose. The pigment production was reduced in sesame seed medium with maltose at $28^{\circ} \mathrm{C}$ when compared to only powdered sesame seed broth. Glucose in powdered sesame seed medium showed a complete decrease of prodigiosin production at both $28^{\circ} \mathrm{C}$ and $30^{\circ} \mathrm{C}$. Amongst the two sugars substituted, maltose acts as a better source of substrate in enhancing pigment production in nutrient broth. This clearly showed that in sesame medium the addition of maltose or glucose does not significantly enhance the pigment production. In fact the addition of glucose or maltose caused a reduction in prodigiosin production which could be due to catabolite repression. The pigment production in nutrient broth with sugars was not more than what was observed in sesame seed medium ${ }^{[1]}$. Sesame oil broth, Peanut oil broth and Coconut oil broth as substrate were more efficient in inducing pigment production when compared to the use of nutrient broth or peptone glycerol broth. The yield was more or less similar when compared to nutrient broth with maltose or glucose as shown in Table 1. The reduction in prodigiosin production by Serratia marcescens mediated by glucose 
Table 1: Comparative analysis of prodigiosin and extracellular protein production by Serratia marcescens in different media at 28,30 and $37^{\circ} \mathrm{C}$ temperatures

\begin{tabular}{|c|c|c|c|c|}
\hline S.No: Media used & $\begin{array}{l}28^{\circ} \mathrm{C} \\
\mathrm{mgml}^{-1}\end{array}$ & $\begin{array}{l}30^{\circ} \mathrm{C} \\
\mathrm{mgml}^{-1}\end{array}$ & $\begin{array}{l}37^{\circ} \mathrm{C} \\
\mathrm{mgml}^{-1}\end{array}$ & References \\
\hline Nutrient broth & 0.52 & 0.354 & 0.111 & [39] \\
\hline $\begin{array}{l}\text { Peptone glycerol } \\
\text { broth }\end{array}$ & 0.302 & 0.569 & 0.111 & [39] \\
\hline Sesame seed broth & 16.68 & 9.3 & 0.319 & [39] \\
\hline Nutrient broth with & 1.836 & 0.79 & 0.104 & [39] \\
\hline $\begin{array}{l}0.5 \% \text { Maltose } \\
\text { Nutrient broth with }\end{array}$ & 1.689 & & & \\
\hline & 9.43 & 0.29 & 0.104 & [39] \\
\hline $\begin{array}{l}\text { with } 0.5 \% \text { Maltose } \\
\text { Sesame seed broth }\end{array}$ & 1.47 & 8.56 & 1.63 & [39] \\
\hline with $0.5 \%$ Glucose & 0.767 & 1.16 & 0.42 & [39] \\
\hline Sesame oil broth & 38.75 & 1.006 & 0.107 & [39] \\
\hline Peanut seed broth & 6.07 & 25.98 & 1.49 & [39] \\
\hline Peanut oil broth & & 0.559 & 0.111 & [39] \\
\hline Copra seed broth & 1.42 & 1.39 & 0.1736 & [39] \\
\hline Coconut oil broth & 13 & 0.05 & 0.177 & [39] \\
\hline $\begin{array}{l}\text { Dextrose broth with } \\
\text { Casein }\end{array}$ & & & & [59] \\
\hline $\begin{array}{l}\text { Ethanol and carbon } \\
\text { source }\end{array}$ & 3 & & & [17] \\
\hline
\end{tabular}

and other metabolizable sugar was due to a decrease in $\mathrm{pH}$ observed in the cell suspensions ${ }^{[24]}$. Taking into consideration the basic role of carbon source in enhancing pigment production, two justifications can be made. The first point is that in nutrient broth, which is basically devoid of carbon source, the addition of maltose or glucose enhanced the pigment production but not so in the case of sesame broth which already has carbon in the form of fatty acids. The decrease in prodigiosin production seen in powdered sesame seed broth with the addition of glucose or maltose could be due to a catabolite repression. Maltose and glucose added in nutrient broth gave a two fold increase in yield over nutrient broth or peptone glycerol broth alone. The second point is that a slight enhanced pigment production was seen in the case of peptone glycerol broth at $30^{\circ} \mathrm{C}$ over nutrient broth at $28^{\circ} \mathrm{C}$ and this could be attributed to the glycerol present as carbon source. This clearly justifies the fact that carbon does support cell growth and thereby prodigiosin production ${ }^{[1]}$. The maximum extracellular protein following 36 hours of incubation was found in peptone glycerol broth at $28^{\circ} \mathrm{C}$ and in the case of nutrient broth and sesame broth maximum extracellular protein was seen at $30^{\circ} \mathrm{C}^{[1]}$. The inherent concentration of protein was maximum in nutrient broth followed by powdered sesame seed broth and powdered peanut broth. Both in nutrient broth and peptone glycerol broth the major components were peptone, meat and yeast extract. Peptone is a commercially available digest of a particular plant or animal protein, made available to organisms as peptides and amino acids to help satisfy requirements for nitrogen, sulfur, carbon and energy. Peptones also contain small amounts of various organic and inorganic compounds ${ }^{[25]}$. But they may be deficient in certain minerals and vitamins. Yeast and meat extracts contain eukaryotic tissues (yeast, beef muscle, liver, brain, heart, etc.) that are extracted by boiling and then concentrated to a paste or dried to a powder. These extracts are frequently used as a source of amino acids, vitamins and coenzymes, growth factors by fastidious organisms. Trace elements, minerals and usually some sugar are also present. In peptone glycerol broth, the glycerol was the carbon source. The seeds and oils contain metals; vitamins, saturated and unsaturated fatty acids and the concentration of these components are variable in each kind of seed or oil ${ }^{[1]}$. Pure saturated and unsaturated fatty acids were substituted in the medium and triolein an unsaturated fatty acid gave the maximum of $0.69 \mathrm{mg} \mathrm{ml}^{-1}$ yield of the pigment ${ }^{[1]}$. Fatty acids as a carbon source also play a role in enhanced cell density thereby an enhanced pigment production. The role of saturated fatty acids as a better carbon source in terms of pigment yield can be discussed with the following points. The overall saturated fatty acid composition is highest in copra, followed by peanut and then sesame. The reason for this could be that $50 \%$ lauric and 7\%capric acid known for their antibacterial activity present in coconut could have inhibited the growth of Serratia marcescens in the medium thereby giving a very low yield. The second point validating the role of saturated fatty acid is that as per literature peanut has a higher concentration than sesame and the yield of prodigiosin is also higher in powdered peanut broth than in powdered sesame broth. According to Kim et al., ${ }^{[26]}$ oil gave a better yield over the various carbon [not fatty acid containing seeds] and nitrogen sources tested. The bonded fatty acids as carbon source are less accessible by Serratia marcescens ${ }^{11]}$.

Prodigiosin structure: The prodigiosin group of natural products is a family of tripyrrole red pigments that contains a common 4-methoxy, 2-2 bipyrrole ring system (Fig. 1). The biosynthesis of the pigment is a bifurcated process in which mono and bipyrrole precursors are synthesized separately and then assembled to form prodigiosin ${ }^{[27]}$. Prodigiosin have been shown to be associated in extracellular vesicles, cell associated or present in intracellular granules ${ }^{[28,29]}$.

Prodigiosin biosynthesis: Prodigiosin is a multifaceted secondary metabolite. It is produced by Serratia marcescens, Pseudomonas magneslorubra, Vibrio psychroerythrous, S. rubidaea, Vibrio gazogenes, Alteromonas rubra, Rugamonas rubra and Gram positive actinomycetes, such as Streptoverticillium rubrireticuli and Streptomyces longisporus ruber form prodigiosin and/or derivatives of this molecule ${ }^{[7,30,31]}$. The actinomycete prodiginines include the linear tripyrrole undecylprodiginine 1 and several isomeric, cyclic derivatives such as butylmetacycloheptylprodiginine 2, ethyl-meta- 


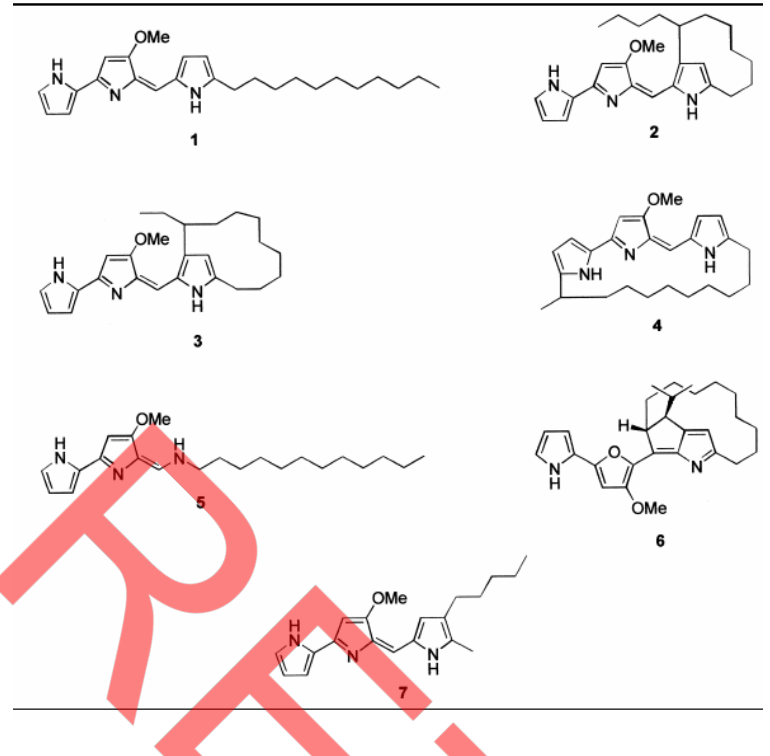

Fig. 1: Structures of some prodiginines produced by actinomycetes 1-6 and the structure of prodigiosin $7^{[30]}$.

cyclononylprodiginine

methylcyclodecylprodiginine 4 (Fig. 1$)^{[32,7]}$. The antitumour antibiotics BE18591 5 and roseophilin 6 (Fig. 1), isolated from Streptomyces sp. BA18591 and Streptomyces griseoviridis respectively, can also be considered as members of the prodiginine family ${ }^{[33,34\}}$. The biosynthesis of prodigiosin (7, Fig. 1) by Serratia marcescens and of several actinomycete prodiginines has been examined by the incorporation of labeled precursors $^{[35,36]}$. A complete pathway for prodiginine biosynthesis has been deduced by analysis of the red cluster in Streptomyces coelicolor A3 (2), including assignment of putative enzymatic functions for the proteins encoded by 16 of the 21 previously uncharacterized genes in the cluster. Confirmation of the role of some of the enzymes in the deduced pathway is provided by gene deletion experiments ${ }^{[37]}$. The studies demonstrated that undecylprodiginine is derived from one unit of proline, one unit of glycine, one unit of serine and several units of acetate, via a convergent pathway involving condensation of 4-methoxy-2,2Pbipyrrole-5-carboxaldehyde (8, Fig. 2) and 2undecylpyrrole (9, Fig. 2) at a late stage. The macrocyclic prodiginines appear to be derived from undecylprodiginine by oxidative cyclisation (Fig. 2). In early genetic studies, mutants defective in prodiginine biosynthesis that had been generated by UV irradiation were grouped into five classes (redA-E) according to their cosynthesis behavior ${ }^{[38]}$. Mapping of these mutations to the $S$. coelicolor chromosome indicated that they were clustered. Subsequently, a gene encoding an O-methyltransferase required for a late step in prodiginine biosynthesis was cloned by complementation of the redE mutation ${ }^{[39]}$.

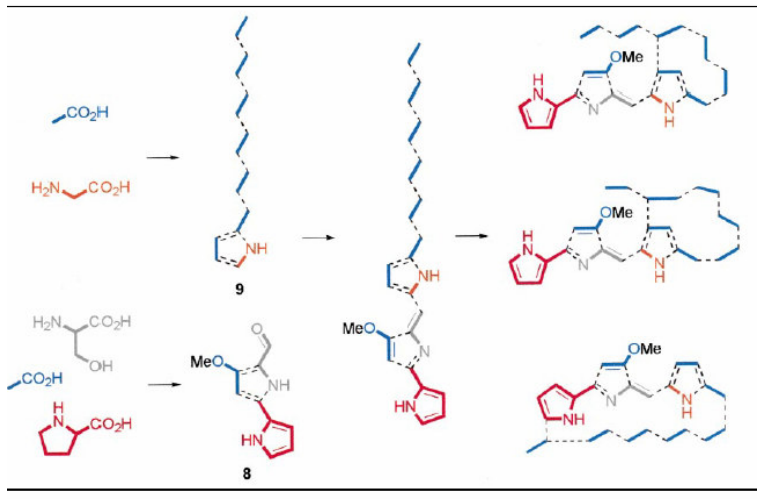

Fig. 2: The biosynthetic origin of undecylprodiginine and three cyclic derivatives deduced from the incorporation of labeled precursors ${ }^{[30]}$

This was followed by the cloning of other biosynthetic genes covering $>21 \mathrm{~kb}$ of the chromosome by complementation of further classes of red mutants, eventually leading to the cloning of the entire prodiginine biosynthesis cluster and its expression in a heterologous host ${ }^{[40,41]}$.

Among the proteins of assigned function, there are homologues of those involved in the biosynthesis of a diverse array of natural products including fatty acid synthases ${ }^{[42]}$, type I modular polyketide synthases ${ }^{[20]}$, no ribosomal peptide synthetases ${ }^{[43]}$ and K-oxoamine synthases - key enzymes in porphyrin and biotin biosynthesis ${ }^{[44,45]}$. The deduced pathway provides a framework for developing a detailed understanding of the mechanisms governing selectivity in key prodiginine biosynthetic enzymes and suggests several strategies for engineering the biosynthesis of novel prodiginines $^{[37]}$. A mutant strain of $S$. marcescens produced nor-prodigiosin, in which the methoxy group of prodigiosin is replaced by a hydroxy group. Another mutant strain produced a blue tetrapyrrole pigment whose structure is a dimer of prodigiosin rings A and B. Three novel biosynthetic analogs of prodigiosin have been obtained using a colorless mutant which does make rings $A$ and $B$ but not ring $C$ and which can couple rings $\mathrm{A}$ and $\mathrm{B}$ with some added monopyrroles similar to ring $\mathrm{C}$. The structures of three prodiginine (prodigiosin-like) pigments from Streptomyces have been elucidated. All have the methoxytripyrrole aromatic nucleus of prodigiosin and all have an 11 carbon aliphatic side chain attached at carbon 2 of ring C. In two of the pigments the side chain is also linked to another carbon of ring $\mathrm{C}$. The earlier literature about prodiginine pigments from actinomycetes has been interpreted and evaluated in light of the most recent findings. The structure elucidation of six prodiginine pigments from Actinomadurae (Nocardiae) has been completed. Only one, undecylprodiginine, is the same as from a Streptomycete. For three of the six pigments, nine carbon side chains are observed and in four of 
them the side chain is attached to carbon 5 of ring $\mathrm{A}$ as well as carbon 2 of ring $\mathrm{C}$ so that a large ring is formed which includes the three pyrrole moieties. The final step in the biosynthesis of prodigiosin was known to be the coupling of methoxybipyrrolecarboxaldehyde (rings A and B) with methylpentylpyrrole (ring C). Recent work using 13C-labeled precursors and Fourier transform 13C nuclear magnetic resonance has shown the pattern of incorporation for acetate, proline, glycine, serine alanine and methionine into prodigiosin. Each pyrrole ring is constructed in a different way ${ }^{[46]}$. Other investigators have reported that most clinical strains form a pigment if furnished with 4-methoxy-2, 2'bipyrrole-5-carboxyaldehyde (MBC), a precursor of prodigiosin. To determine whether the pigment was prodigiosin, 65 white strains of $S$. marcescens isolated from patients. On the basis of response to $\mathrm{MBC}$, the strains to one of three classes: class 1 (14 strains), strains remaining white; class 2 (48 strains), strains becoming gray or pink; and class 3 (3 strains), strains becoming blue. Ethanol extracts of bacteria of classes 2 and 3 did not behave like prodigiosin when acidified or alkalinized and the pigment spectra were not similar to prodigiosin spectra. If strains of class 3 were furnished with MBC plus 2-methyl-3-amylpyrrole (MAP), the other immediate precursor of prodigiosin, the pigment synthesized was characteristic of prodigiosin. Strains of classes 1 and 2 responded identically to MBC plus MAP and MBC alone. Although the majority of $S$. marcescens white strains from patients formed pigments in the presence of $\mathrm{MBC}$, the pigments were not prodigiosin. A few strains did synthesize prodigiosin, but only if furnished with both $\mathrm{MBC}$ and $\operatorname{MAP}^{[6]}$.

\section{Prodigiosin production inhibitory factors}

Inorganic phosphate: The studies demonstrated that synthesis of prodigiosin by non-proliferating cells of Serratia marcescens is depended to presence of inorganic phosphate (Pi) concentrations. A high elevation of pigment formation was obtained at less than or equal to $0.3 \mathrm{mM}$ and a broader but much lower elevation was obtained at 10 to $250 \mathrm{mM} \mathrm{Pi}$. The synthesis of two immediate precursors of the pigment also was inhibited by $\mathrm{Pi}$. The mechanism of action of $\mathrm{Pi}$ did not involve changes in $\mathrm{pH}$ or accumulation of the trace metal nutrient iron or zinc. Inhibition was most pronounced when $\mathrm{Pi}$ was added to the induction system before the onset of pigment formation. The inhibitor also diminished the burst of alkaline phosphatase activity that occurred in the period between the start of induction and appearance of prodigiosin ${ }^{[47]}$.

Inorganic phosphate and ribose inhibited prodigiosin formation in Serratia marcescens, but adenine did not and ATP was not hydrolyzed by the organism during the experiment ${ }^{[48]}$.
Amino acids: Addition of alanine, proline, or histidine to non-proliferating cells incubated at $27^{\circ} \mathrm{C}$ increased the rate of protein synthesis and also caused biosynthesis of prodigiosin. No increase in the rate of protein synthesis was observed upon the addition of amino acids that did not stimulate prodigiosin biosynthesis. Increased rates of synthesis of ribonucleic acid (RNA) and of deoxyribonucleic acid (DNA) (a small amount) also occurred after addition of amino acids that resulted in biosynthesis of prodigiosin. After incubation of $24 \mathrm{~h}$, the total amount of protein in suspensions of bacteria to which alanine or proline was added increased 67 and 98\%, respectively. Total amounts of DNA and of RNA also increased before synthesis of prodigiosin. The amounts of these macromolecules did not increase after addition of amino acids that did not induce biosynthesis of prodigiosin. However, macromolecular synthesis was not related only to prodigiosin biosynthesis because the rates of DNA, RNA and protein synthesis also increased in suspensions of bacteria incubated with proline at $39^{\circ} \mathrm{C}$, at which temperature no prodigiosin was synthesized. The quantities of DNA, RNA and protein synthesized were lower in non-proliferating cells than in growing cells. The data indicated that amino acids causing biosynthesis of prodigiosin in nonproliferating cells must be metabolized and serve as sources of carbon and of nitrogen for synthesis of macromolecules and intermediates. Prodigiosin was synthesized secondarily to these primary metabolic events [49]. Nonproliferating cells of Serratia marcescens, wild-type strain Nima, synthesized the pigment, prodigiosin, when saline suspensions were incubated with aeration at $27^{\circ} \mathrm{C}$ in the presence of proline or alanine. Mutants PutS1 and PutS2 derived from strain Nima formed prodigiosin from alanine, but not from proline, unless alanine also was added. Strain Nima utilized proline as a sole source of carbon and of nitrogen for growth, whereas Put mutants did not. Investigation of enzymes degrading proline showed that the wild-type strain contained proline oxidase, which was absent in Put mutants. The wild type, as well as the mutants, was utilized alanine as the sole source of carbon and nitrogen for growth. Although Nonproliferating cells of Put mutants failed to synthesize prodigiosin from proline, addition of L-\{U14C $\}$ proline to suspensions metabolizing and synthesizing the pigment because of addition of alanine resulted in the incorporation of radioactive label into prodigiosin, as well as into cellular protein. Since Put mutants could not catabolize proline, the incorporation of $\{14 \mathrm{C}\}$ proline into the prodigiosin molecule indicated that proline was incorporated directly into the pigment ${ }^{[50]}$. 
Glucose: Glucose was found to cause severe repression of prodigiosin production in Serratia marcescens and a dose related partial reversal was demonstrated by theophylline. It is suggested that this reversal is due to the inhibition of cAMP phosphodiesterase and the concomitant increase in cellular cAMP concentration [51].

Respiration activity: The respiration rate of a pigmented strain decreased earlier than that of non pigmented strains in the late exponential or early stationary phase. However when prodigiosin synthesis was not induced by exchange of carbon sources in the medium, the decrease in the respiration rate of the pigmented strain was the same as that of non pigmented strains. Measurement of the oxygen consumption rate in the sonicated cell membrane by adding NADH solution showed that the rate in the pigmented strain was lower than that in non pigmented strains. Furthermore, the cell membrane of prodigiosin-induced organisms was more sensitive to respiration inhibitors than that of pigmentnon induced organisms of the pigmented strain. These results showed that the respiration activity was decreased by prodigiosin synthesis in $S$. marcescens ${ }^{[52]}$.

Genetic: The products of the flhDC operon, FlhD and FlhC, are global gene regulators in enteric bacteria. For example, the expression of many genetic determinants involved in cell division, cell differentiation, swarming/swimming motility and virulence is controlled by flhDC ${ }^{[44,53-59]}$. That the flhDC operon is an important regulator was first noted in a hierarchical system that controls the synthesis of the bacterial flagellum in Escherichia coli ${ }^{[60]}$. Homologues have subsequently been described in Shigella species, Salmonella typhimurium, Serratia liquefaciens and Proteus mirabilis $^{[1,33,61,62]}$. In Serratia marcescens, an important opportunistic human pathogen ${ }^{[63,60]}$, the differentiation of swarmer cells involves a change from short motile vegetative cells with a few peritrichous flagella to multinucleate, aseptate swarm cells that are 40-80 times larger and exhibit overproduction of surface flagella ${ }^{[64,65]}$. Eberl et al. ${ }^{[54]}$ showed that the flhDC operon of S. liquefaciens, when artificially over expressed in LB broth culture, initiates the swarmer cell differentiation of S. liquefaciens. Using cell elongation, flagella over synthesis and the expression pattern of hag (the gene encoding the flagellin subunit, as shown by Harshey et al. $^{[66]}$ as markers for swarmer cell differentiation, demonstrate in S. marcescens that cells with differentiation characteristics can be observed in LB broth culture without artificial over expression of the $f l h D C$ operon $^{[67]}$. Thus, it is possible that cell differentiation is growth phase dependent and occurs under normal physiological conditions when the $f l h D C$ operon reaches peak expression in $S$. marcescens. Whether factors in the rich media also play a role in the initiation of cell differentiation is still unknown ${ }^{[68]}$.
S. marcescens produces a number of virulence factors, including protease, chitinase and lipase, that are substrate regulated ${ }^{[69]}$. Unlike most catabolic enzymes, the expression of the nuclease gene, писA, in $S$. marcescens is not regulated by substrate catabolite repression, but by an SOS-like system ${ }^{[70]}$ and a growth phase-dependent system which is independent of SOS induction ${ }^{[69]}$. Since the dominant genetic regulator of nucASm expression in S. marcescens remains to be identified and expression of the virulence factor phospholipase is regulated by the $f l h D C$ operon in $S$. liquefaciens, ${ }^{[68]}$. In S. marcescens, the flhDCSm operon activates the expression of the nuclease gene nucASm, in addition to the activation of phospholipase gene expression, control of cellular motility and cell division [68]. Serratia marcescens mutants defective in production of the red pigment prodigiosin and the biosurfactant serrawettin W1 in parallel were isolated by transposon mutagenesis of strain 274 . Cloning of the DNA fragment required for production of these secondary metabolites with different chemical structures pointed out a novel open reading frame (ORF) named $p s w P$. Since serrawettin $\mathrm{W} 1$ belongs to the cyclodepsipeptides, which are biosynthesized through the NRPSs system and one pyrrole ring in prodigiosin has been reported as a derivative of Lproline tethered to phosphopantetheinylated PCP, the mutation in the single gene $p s w P$ seems responsible for parallel failure in production of prodigiosin and serrawettin $\mathrm{W} 1^{[71]}$.

Prodigiosin gene expression: Assays of bacterial gene expression make attractive teaching tools for several reasons. First, bacteria modulate their gene expression quickly in response to environmental cues such as cell density, growth temperature and growth medium. Bacterial messenger RNA molecules are typically degraded with half-lives measured in minutes versus the hours of stability for eukaryotic transcripts. Second, many bacteria express pigments under certain conditions. Because most pigments absorb light at some defined wavelength, pigment expression may be easily monitored spectrophotometrically. Third and perhaps most importantly, bacteria are easy to propagate in the teaching laboratory ${ }^{[72]}$. Prodigiosin is expressed as a secondary metabolite in the general method of gene expression called quorum sensing $[62,73]$. Growth in liquid culture at low cell density allows low-level expression of a membrane permeable positive regulator of prodigiosin expression. The intracellular concentration of the regulator remains low at low cell density due to its diffusion across the cell membrane after synthesis. However, as cell density increases in a closed system, the intracellular concentration of regulator increases to a threshold needed for activation of prodigiosin expression. Thus, high levels of prodigiosin are expressed in liquid culture only at high cell density. A similar phenomenon operates with 
colonies grown from single cells on agar plates ${ }^{[74]}$. Very small and widely spaced colonies are initially non-pigmented; coloration first develops near a colony diameter of about 1 millimeter ${ }^{[72]}$.

Apoptotic effect of prodigiosin: Apoptosis is a form of cell death in which cells actively participate in their own destructive processes. This process is characterized by morphological ${ }^{[38,75,76]}$ and biochemical/molecular $[77,38,76]$ criteria. Cells undergoing apoptosis shrink and lose their normal intercellular contacts and subsequently exhibit cytoplasmic and chromatin condensation and internucleosomal cleavage of DNA. In the final stages, cells become fragmented into small apoptotic bodies, which are then eliminated by phagocytosis. Several bacterial pathogens have been identified as mediators of apoptosis in vitro and during pathogenesis ${ }^{[78]}$. These pathogens have developed different strategies to survive inside the host, overcome natural defenses and thus cause disease. Induction of host immunosuppression by triggering apoptosis in phagocytes, like polymorph nuclear neutrophils (PMN) and macrophages, might represent an advantage in bacterial invasion, since these are the most dangerous cells for bacteria. Several pathogens like Shigella spp [79] and Salmonella spp [80-82] induce apoptosis in macrophages. Furthermore, the induction of PMN apoptosis by Actinobacillus actinomycetemcomitans has been suggested ${ }^{[83]}$. Bacterial toxins like leukotoxin, atoxin and haemolysin form pores in the eukaryotic cell membrane and disrupt the cell via osmotic swelling [41, ${ }^{84,85]}$. Other toxins like diphtheria toxin and exotoxin A inhibit protein synthesis, causing apoptosis in eukaryotic cells ${ }^{[86,87]}$. Yoshida et al. ${ }^{[88]}$ identified an acidic glycoprotein purified from the crude extract of Streptococcus pyogenes $\mathrm{Su}$, which showed cell growth inhibition in vitro and antitumour activity in vivo. Vero toxin 1, the active component of the bacteriocin preparation from Escherichia coli, induces apoptosis in human cancer cell lines ${ }^{[32]}$ and eliminates human astrocytoma xenografts ${ }^{[89]}$. The prevention of neoplasia by agents from bacteria that inhibit cancer cell proliferation but are not toxic to healthy cells is an exciting prospect. Apoptosis is involved in the action of several cancer- chemotherapeutic agents. In the last few years, the selection of new drugs associated with apoptosis that would be expected to be effective against tumors with high proliferation like leukemias and lymphomas has been introduced into screening for new anticancer drugs ${ }^{[90]}$. Prodigiosin released from $S$. marcescens 2170 to the culture medium induced apoptosis in four haematopoietic cancer cell lines (Jurkat, NSO, HL-60 and Ramos) but not in nonmalignant cells (NIH-3T3 and MDCK). Furthermore, prodigiosin is equally active in other cancer cell lines like SW-620, DLD-1 and HGT-1 (all of gastrointestinal origin) and indicates that prodigiosin may have potential as new antineoplastic candidate ${ }^{[91]}$.
In 1998, Han et al. ${ }^{[92]}$ described a T-cell specific immunosuppression associated to prodigiosin; however, they showed that prodigiosin did not cause significant decrease in the splenic lymphocyte viability for $24 \mathrm{~h}$ of incubation at concentrations from 1 to $1000 \mathrm{nM}$, similar to our results in nonmalignant NIH-3T3 cells ${ }^{[91]}$. UP inhibits equally well both $\mathrm{T}$ and $\mathrm{B}$ human lymphocyte proliferation, but not transformed leukaemic cell lines ${ }^{[24]}$, suggested that cell-cycle related proteins such as retinoblastoma $(\mathrm{Rb})$ and cyclin-dependent Kinase-2 and $-4(\mathrm{Cdk}-2$ and Cdk-4) are the target molecules of UP to induce growth arrest in $\mathrm{G}$ human $\mathrm{T}$ and $\mathrm{B}$ lymphocytes. Mortellaro et al. ${ }^{[93]}$ reported that a synthetic analogue of UP, PNU156804, has a biological effect indistinguishable from UP and efficiently inhibits the activation of NF-kB and AP-1 transcription factors. Inhibition of NF-kB substantially enhances the apoptotic potential of cancer therapies ${ }^{[94]}$. However, Kawauchi et al. ${ }^{[95]}$ and Azuma et al. ${ }^{[96]}$ suggested that apoptosis is the mechanism of action of $\mathrm{cPrGHCl}$ to induce suppression of $\mathrm{T}$ cell proliferation. The molecule cPrGHCl inhibits proliferation and induces apoptosis in hepatocellular carcinoma cell lines, showing IC values from 276 to $592 \mathrm{nM}$, compared with $8395 \mathrm{nM}$ in isolated normal rat hepatocytes, at $72 \mathrm{~h}^{[97]}$. The results show an IC for prodigiosin of $225 \mathrm{nM}$ in Jurkat in a shorter assay $(4 \mathrm{~h})$. However, the mechanisms underlying the apoptotic effect of prodigiosin are unknown. cPrGHCl inhibits vacuolar ATPase ${ }^{[98]}$ and like other vacuolar ATPase inhibitors, it acidifies the cytoplasm and apoptosis [ ${ }^{[99]}$. The results showed that prodigiosin-induced apoptosis is blocked by ZVAD.fmk, indicating that these caspases are involved in prodigiosin-induced apoptosis in haematopoietic cancer cell lines ${ }^{[91]}$. Interestingly, prodigiosin induces apoptosis in Jurkat and HL-60 cells, both of which are p53 deficient ${ }^{[14]}$. This evidence indicates that prodigiosin-induce apoptosis by a p53-independent mechanism. Oncogenesis is often associated with defects in p53. As prodigiosin-induced apoptosis is p53-independent, this could mean an advantage over other chemotherapeutic drugs ${ }^{[100,101]}$. The elucidation of the mechanisms involved in the apoptotic action of prodigiosin and its evaluation as a possible anticancer drug warrants further investigation ${ }^{[102]}$ among different apoptosis of B and T cells from B-CLL samples ${ }^{[103]}$. This is the first report showing that prodigiosin induces apoptosis in human primary cancer cells ${ }^{[103]}$. The researches demonstrated that prodigiosin induces apoptosis of human haematopoietic cancer cell lines derived from acute T-cell leukemia, promyelocytic leukemia, myeloma and Burkitt lymphoma [102]. Prodigiosin also induces apoptosis in cells derived from other human tumors ${ }^{[102,104]}$. Cycloprodigiosin, another member of the prodigiosin family, induces apoptosis in various cancer cell lines including acute human T-cell leukemia ${ }^{[95]}$ promyelocytic leukemia ${ }^{[105]}$ human and rat hepatocellular cancer ${ }^{[97]}$ human breast cancer ${ }^{[79]}$ and 
TNF-stimulated human cervix carcinoma (HeLa) ${ }^{[106]}$. The National Cancer Institute (Bethesda) has also shown that prodigiosin has an average IC50 of 116725 $\mathrm{nM}{ }^{[103]}$. The effect of prodigiosins on normal lymphocytes is more controversial. It has been reported that prodigiosin inhibits the proliferation of murine splenic $\mathrm{T}$ lymphocytes at nontoxic concentrations with no effect on B-cell proliferation [96,107]. Contrast, cycloprodigiosin induces apoptosis of activated murine splenic $\mathrm{T}$ cells ${ }^{[96]}$. Although the toxicity of prodigiosin for normal human B cells has not been tested, the results presented here show that $\mathrm{B}$ and $\mathrm{T}$ cells from $\mathrm{B}-$ CLL samples have the same sensitivity to prodigiosininduced apoptosis.

Drawbacks: The mechanism by which prodigiosin induces apoptosis is unknown ${ }^{[103]}$. Other prodigiosins lack apoptotic activity, thus undecylprodigiosin and its derivative PNU15804 inhibit the proliferation of human $\mathrm{B}$ and $\mathrm{T}$ lymphocytes with no effects on cell death, ${ }^{[91,108]}$ indicating that they may act through a different mechanism. PNU156804 blocks IL-2dependent NF-kB and AP-1 activation ${ }^{[91]}$ and it is a selective inhibitor of Janus tyrosine kinase 3(Jak3) ${ }^{[111]}$. Current B-CLL therapies do not demonstrate specificity, thus fludarabine is cytotoxic for $\mathrm{T}$ lymphocytes ${ }^{[109,110]}$. Interestingly, in a subset of samples, prodigiosin is less toxic than fludarabine for normal $\mathrm{T}$ cells, while having similar effect in B-CLL cells. Furthermore, prodigiosin induces apoptosis in BCLL cells that are resistant to treatment with fludarabine ${ }^{[103]}$. Cycloprodigiosin also inhibits NF-kB activation ${ }^{[106]}$ although prodigiosin does not ${ }^{[46]}$. Taken together, these results suggest that inhibition of these signaling pathways cannot explain the apoptotic activity of prodigiosins in $\mathrm{B}$ and $\mathrm{T}$ lymphocytes ${ }^{[103]}$. In vitro, prodigiosin binds to DNA, facilitating oxidative double-strand DNA cleavage that correlates with cytotoxicity ${ }^{[111]}$. DNA damage induces the accumulation of p53 tumor suppressor protein ${ }^{[112]}$. However, p53 was not induced by prodigiosin in BCLL cells. Furthermore, prodigiosin induces apoptosis in Jurkat and HL-60 cells that are p53-deficient ${ }^{[102]}$. These results suggest that prodigiosin induces apoptosis independently of p53 and DNA damage ${ }^{[103]}$. Prodigiosins promote $\mathrm{H}^{+} / \mathrm{Cl}^{-}$a symport activity leading to acidification of the cytosol. This activity has been implicated in cycloprodigiosin-induced apoptosis because imidazole inhibits both acidification and apoptosis in different human cancer cell lines ${ }^{[105,97,105]}$. This is the first report showing that prodigiosin induces apoptosis in human primary cancer cells. Understanding the mechanism of prodigiosin-induced apoptosis and identification of its molecular target would help to design more potent agents to induce apoptosis of B-CLL cells ${ }^{[103]}$.
Toxigenic effect of prodigiosin: The effects of prodigiosin and its fractions PE-1, C-2, A-3, E-4, were extracted in five organic solvents, petroleum ether, chloroform, acetone, ethanol and methanol, on embryogenesis showed the whole pigment and C-2 fraction to be highly toxigenic while other fractions demonstrated toxicities approaching LD50 values of 26-30 mug $\mathrm{egg}^{-1}$ when dissolved in $100 \%$ dimethyl sulfoxide. The E-4 fraction in DMSO was least toxic. 95\% ethanol proved to be highly toxic at a dose level of $0.1 \mathrm{ml} \mathrm{egg}^{-1}$ indicating that it was an unsuitable solvent for studies of this nature. Disc-agar diffusion sensitivity studies were performed against E.coli, E aerogenes, $S$. aureus, B. subtilis and $P$. aeruginosa with prodigiosin and fractions dissolved in $100 \%$ DMSO. The solvent was found to have no diffusible bacteriostatic activity in vitro. However, prodigiosin and the ethanol (E-4) and methanol (M-5) fractions produced inhibition zones with every organism tested. Data indicate that prodigiosin extracts have toxigenic effects on chick embryos and inhibit the growth of several species of bacteria $^{[113]}$.

\section{CONCLUSION}

Prodigiosins, a family of natural red pigments characterized by a common pyrrolylpyrromethane skeleton, are produced by various bacteria that first characterized from Serratia marcescens. In this particular species, very small and widely spaced colonies are initially non-pigmented; coloration first deyelops near a colony diameter of about 1 millimeter ${ }^{[72]}$. Serratia marcescens expresses pigments under certain conditions. Because most pigments absorb light at some defined wavelength, pigment expression may be easily monitored spectrophotometrically. This promising pigment has having antifungal, immunosuppressive and antiproliferate activity and consider being a protein. This particular protein of assigned functions are homologues of those involved in the biosynthesis of a diverse array of natural products including fatty acid synthases, type I modular polyketide synthases, no ribosomal peptide synthetases ${ }^{[43]}$. The apoptotic effect of prodigiosin is concluded by various researchers ${ }^{[24,91-96]}$. The assignment of putative enzymatic functions for this particular proteins encoded by 16 of the 21 previously uncharacterized genes in the cluster. Confirmation of the role of some of the enzymes in the deduced pathway is provided by gene deletion experiments ${ }^{[37]}$. Prodigiosin family has various members such as Cycloprodigiosin, This particular compound induces apoptosis in various cancer cell lines including acute human T-cell leukemia, promyelocytic leukemia, and ${ }^{[95,105]}$ human and rat hepatocellular cancer ${ }^{[97]}$ human breast cancer ${ }^{[79]}$ and TNF-stimulated human cervix carcinoma 
(HeLa) ${ }^{[106]}$. Prodigiosins promote $\mathrm{H}^{+} / \mathrm{Cl}^{-}$a symport activity leading to acidification of the cytosol. This activity has been implicated in cycloprodigiosininduced apoptosis because imidazole inhibits both acidification and apoptosis in different human cancer cell lines ${ }^{[106,97,105]}$. Under-standing the mechanism of prodigiosin-induced apoptosis and identification of its molecular target would help to design more potent agents to induce apoptosis of B-CLL cells ${ }^{[103]}$. Prodigiosin can be extracted with organic solvents, petroleum ether, chloroform, acetone, ethanol and methanol. Several different compounds have toxigenic effect of prodigiosin. The effects of prodigiosin and its fractions on embryogenesis showed the whole pigment and C-2 fraction to be highly toxigenic while other fractions demonstrated toxicities approaching LD50 values of $26-30$ mug $\mathrm{egg}^{-1}$ when dissolved in $100 \%$ dimethyl sulfoxide. The E-4 fraction in DMSO was least toxic. $95 \%$ ethanol proved to be highly toxic at a dose level of $0.1 \mathrm{ml} \mathrm{egg}^{-1}$ indicating that it was an unsuitable solvent for studies of this nature.

\section{REFERENCES}

1. Giri, A.V., N. Anandkumar, G.Muthukumaran and G. Pennathur, 2004. A novel medium for the enhanced cell growth and production of prodigiosin from Serratia marcescens isolated from soil. BMC Microbiology, 4: 11

2. Hejazi, A. and F.R. Falkiner, 1997. Serratia marcescens. J. Med. Microbiol., 46: 903-912.

3. Singlton, P. and D. Sainsbury, 2001. Dictionare of Microbiology and Molecular Biology. 3rd Edn. Johan Willy and Sons Ltd.

4. Law, R., 2001. A. Provided by Karen Fujii, Division of Outbreak Investigation, Marylan Department of Health and Mental Hygiene, Vol. 20, No. 49.

5. Carbonell, T., H.H.M. Della Colleta, T. Yano, A.L.C. Darini, C.E. Levy and B.A.L. Fonseca, 2000. Clinical relevance and virulence factors of pigmented Serratia marcescens. A low frequency of isolation of pigmented Serratia marcescens $<$ http://www.ncbi.nlm.nih.gov/entrez/query.fcgi?cmd=Retrieve $\& \mathrm{db}=$ PubMed \&dopt=Abstract\&list_uids=10.1016/S0928-8244 (00)00146-2>from clinical specimens, indicating that non pigmented strains are clinically more significant FEMS. Immunol. Microbiol. Mtds., 28: 143-149.

6. Ding, M.J. et al., 1983. Biosynthesis of prodigiosin by white strains of Serratia marcescens isolated from patients. J. Clin. Microbiol., 17: 476-80.

7. Austin, D.A. and M.O. Moss, 1986. Numerical taxonomy of red pigmented bacteria isolated from a lowland river, with the bacteria isolated from a lowland river, with the description of a new taxon, Rugamonas rubra gen. nov., sp. nov. J. Gen. Microbiol., 132: 1899-1909.
8. Hines, D.A., P.N. Saurugger, G.M. Ihler and M.J. Benedik, 1988. J. Bacteriol., 170: 4141.

9. Monreal, J. and E. Reese, 1969. Can. J. Microbiol., 15: 689.

10. Fuchs, R.L., S.A. McPherson and D.J. Drahos, 1986. Appl. Environ. Microbiol., 51: 504.

11. Suzuki, K., M. Suzuki, M. Taiyoji, N. Nikaidou and T. Watanabe, 1998. Biosci. Biotechnol. Biochem., 62: 128.

12. Brurberg, M.B., I.F. Nes and V.G.H. Eijsink, 1996. Microbiology, 142: 1581.

13. Gal, S.W., J.Y. Choi, C.Y. Kim, Y.H. Cheong, Y.J. Choi, S.Y. Lee, J.D. Bahk and M.J. Cho, 1998. FEMS Microbiol. Lett., 160: 151.

14. Chen, E. and M. Haas, 1990. Frequent mutations in the p53 tumor suppressor gene in human leukemia T-cell lines. Mol. Cell Biol., 10: $5502 \pm 5509$.

15. Synstad, B. et al., 2000. Chitinases from Serratia marcescens, Research Developments in Microbiology.

16. Nobutaka, S., N. Masami, H. Kazuyuki, H. Tadaaki and A. Katsumi, 2001. Synergistic antifungal activity of chitinolytic enzymes and prodigiosin produced by biocontrol bacterium, Serratia marcescens strain B2 against gray mold pathogen, Botrytis cinerea. J. Gen. Plant Pathol., 67: 312-319.

17. Mandarville, R.A., 2001. Synthesis, Proton affinity and Anticancer $<$ http://www.ncbi.nlm.nih.gov/entrez/query.fcgi?cmd=Retrieve $\& \mathrm{db}=$ PubMed $\&$ dopt $=$ Abstract \&list_uids=12678767> properties of the prodigiosin group of natural product. Current Med. Chem., 1: 195-218.

18. Hiroaki, M., A. Hiroyuki, F. Masakatsu, S. Takeji and T. Teisuya, 1996. Industrial production of optically active intermediate in the synthesis of dialtizem with lipase. Seibutsu-kogaku, 74: 273288.

19. Pryce, L.H. and F.W. Terry, 2000. Spectrophotometric assay of gene expression: Serratia marcescens Pigmentation. Bioscience, 26: 3-13.

20. Staunton, J. and B. Wilkinson, 1997. Biosynthesis of erythromycin and rapamycin. Chem. Rev., 97: 2611-2629.

21. Jonas, D., B. Schultheis, C. Klas, P.H. Krammer and S. Bhakdi, 1993. Cytocidal effects of Escherichia coli hemolysin on human $\mathrm{T}$ lymphocytes. Infect. Immun., 61: $1715 \pm 1721$.

22. Nakamura, 1981. Patent No: 4,266,028.

23. Chang, S., M. Sanada, O. Johdo, S. Ohta, Y. Nagamatsu and A. Yoshimoto, 2000. High production of prodigiosin by Serratia marcescens grown<http://www.ncbi.nlm.nih.gov/entrez/query.fcgi?cmd=R etrieve \&db=PubMed\&dopt=Abstract\&list_uids=10.1023/A:100 5646102723> on ethanol. $<$ http://www.ncbi.nlm.nih.gov/entrez/query.fcgi?cmd=Retrieve $\& \mathrm{db}=$ PubMed \&dopt=Abstract\&list_uids=10.1023/A:10056461 02723>Biotechnol. Lett., 22: 1761-1765. 
24. Solé, M., A. Francia, N. Rius and J.G. Lorén, 1997. The role of $\mathrm{pH}$ in the "glucose effect" on prodigiosin production by non-proliferating cells of Serratia marcescens. Lett. Appl. Microbiol., 25: 81-84.

25. Lindquist, J.A. Nutrition and Cultivation of Bacteria - Appendi-ces d.1 and E.1 in General Microbiology - A Laboratory Man-ual. McGrawHill/Primis Custom Publishing ISBN 0-07-2359064

26. Kim, C.H., K. Sung-Ho and K. Suk-In, 1998. Isolation and Characteristics of prodigiosin like red pigment produced by Serratia sp. KH-95. Kor. J. Appl. Microbiol. Biotechnol., 26: 283-289.

27. Boger, D.L. and M. Patel, 1988. Total synthesis of prodigiosin, prodigiosene and desmethoxyprodigiosin: Diels-Alder reactions of hetero cyclic azidenes and development of an effective palladium (II)-promoted 2'2'-bipyrrole coupling procedure. J. Org. Chem., 53: 1405-1415.

28. Kobayashi, N. and Y. Ichikawa, 1991. Separation of the prodigiosin localizing crude vesicles which retain the activity of protease andnuclease in Serratia marcescens. http://www. ncbi.nlm.nih .gov/entrez/query.fcgi? $c m d=$ Retrieve $\& d b=P u b M e d \& d o p t=A b s t$ ract\&list_uids=1753881 Microbiol. Immunol., 35: 607614.

29. Matsuyama, T., T. Murakami, M. Fujita, S. Fujita and I. Yano, 1986. Extracellular vesicle formation and biosurfactant production by Serratia marcescens. J. Gen. Microbiol., 132: 865-875.

30. Gerber, N.N., 1975. Prodigiosin like pigments. $<$ http://www.ncbi.nlm.nih.gov/entrez/query.fcgi?cmd=Retrieve $\& \mathrm{db}=$ PubMed $\&$ dopt $=$ Abstract\&list_uids $=1095305>$ CRC Crit. Rev. Microbiol., 3: 469-485.

31. Rowan, S. and D.E. Fisher, 1997. Mechanisms of apoptotic cell death. Leukemia, 11: $457 \pm 465$.

32. Arab, S., M. Murakami, P. Dirks, B. Boyd, S. Hubbard, D. Lingwood and J. Rutka, 1998. Verotoxins inhibit the growth of and induce apoptosis in human astrocytoma cells. J. Neurol. Oncol., 40: $137 \pm 150$.

33. Kojiri, K., S. Nakajima, H. Suzuki, A. Okura and H. Suda, 1993. A new antitumor substance, Be18591, produced by a streptomycete. 1 . Fermentation, isolation, physicochemical and biological properties. J. Antibiot., 46: 1799-1803.

34. Hayakawa, Y., K. Kawakami, H. Seto and K. Furihata, 1992. Structure of a new antibiotic, roseophilin, Tetrahedron Lett., 33: 2701-2704.

35. Gerber, N., A. McInnes, D. Smith, J. Walter, J. Wright and L. Vining, 1997. Biosynthesis of prodiginines. $13 \mathrm{C}$ assignments and enrichment patterns in nonyl-, cyclononyl-, methylcyclodecyland butylcycloheptylprodiginine produced by actinomycete cultures supplemented with 13Clabeled acetate and 15N-labeled nitrate. Can. J. Chem., 56: 1155-1163. Chem. Rev., 97: 26112629.
36. Wasserman, H.H., R.J. Sykes, P. Peverada, C.K. Shaw, R.J. Cushley and C.R. Lipsky, 1973. Biosynthesis of prodigiosin. Incorporation patterns of C-labeled alanine, proline, glycine and serine elucidated by fourier transform nuclear magnetic resonance. J. Am. Chem. Soc., 95: 6874-6875.

37. Cerden“o, A.M., M.J. Bibb and G.L. Challis, 2001. Analysis of the prodiginine biosynthesis gene cluster of Streptomyces coelicolor A 3(2): new mechanisms for chain initiation and termination in modular multienzymes. Chem. \& Biol., 8: 817-829.

38. Rudd, B.A.M. and D.A. Hopwood, 1980. A pigmented mycelial antibiotic in Streptomyces coelicolor: control by a chromosomal gene cluster. J. Gen. Microbiol., 119: 333-340.

39. Feitelson, J.S. and D.A. Hopwood, 1983. Cloning of a Streptomyces gene for an O-methyltransferase involved in antibiotic biosynthesis, Mol. Gen. Genet., 190: 394-398.

40. Feitelson, J.S., F. Malpartida and D.A. Hopwood, 1985. Genetic and biochemical characterization of the red gene cluster of Streptomyces coelicolor A3(2). J. Gen. Microbiol., 131: 2431-2441.

41. Mangan, D.F., N.S. Taichman, E.T. Lally and S.M. Wahl, 1991. Lethal effects of Actinobacillus actinomycetemcomitans leukotoxin on human $\mathrm{T}$ lymphocytes. Infect. Immunol., 56: $3267 \pm 3272$.

42. Rock, C.O. and J.E. Cronan, 1996. Escherichia coli as a model for the regulation of dissociable (type II) fatty acid biosynthesis. Biochim. Biophys. Acta, 1302: 1-16.

Konz, D. and M.A. Marahiel, 1999. How do peptide synthetases generate structural diversity? Chem. Biol., 6: R39-R48.

44. Pruss, B.M., D. Markovic and P. Matsumura, 1997. The Escherichia coli flagellar transcriptional activator flhD regulates cell division through induction of the acid response gene cadA. J. Bacteriol., 179: 3818-3821.

45. Zaman, Z., P.M. Jordan and M. Akhtar, 1973. Mechanism and stereochemistry of the 5aminolaevulinate synthetase reaction. Biochem. J., 135.

46. CRC Crit. Rev. Microbiol,, 1975. May, 3: 469-85.

47. Witney, F.R. et al., 1977. Phosphate inhibition of secondary metabolism in Serratid marcescens. Appl. Environ. Microbiol., 33: 1042-6.

48. Lawanson, A.O. et al., 1976. Inhibition of prodigiosin formation in Serratia marcescens by adenosine triphosphate. Experientia, 15, 32: 43940.

49. Williams, R.P. et al., 1976. Macromolecular syntheses during biosynthesis of prodigiosin by Serratia marcescens. Appl. Environ. Microbiol., 31: 70-7.

50. Scott, R.H. et al., 1976. Role of L-proline in the biosynthesis of prodigiosin. Appl. Environ. Microbiol., 32: 561-6. 
51. Clements-Jewery, S., 1976. The reversal of glucose repressed prodigiosin Serratia marcescens production in Serratia marcescens by the cyclic 3'5'-adenosine monophosphate inhibitor theophylline. Experientia, 15, 32: 421-2.

52. Kobayashi, N. et al., 1985. Decrease in respiration activity related to prodigiosin synthesis in Serratia marcescens, Microbiol. Immunol., 29: 301-8.

53. Dufour, A., R.B. Furness and C. Hughes, 1998. Novel genes that upregulate the Proteus mirabilis flhDC master operon controlling flagellar biogenesis and swarming. Mol. Microbiol., 29: $741-751$.

54. Eberl, L., G. Christiansen, S. Molin, M. Givskov, L.J. Guynn, W. Dai and M.J. Benedik, 1996. Differentiation of Serratia liquefaciens into swarm cells is controlled by the expression of the flhD master operon. J. Bacteriol., 178: 554-559.

55. Givskov, M., L. Eberl, G. Christiansen, M.J. Benedik and S. Molin, 1995. Induction of phospholipase- and flagellar synthesis in Serratia liquefaciens is controlled by expression of the flagellar master operon fthD. Mol. Microbiol., 15: 445-454.

56. Givskov, M., J. Ostling, L. Eberl, P.W. Lindum, A.B. Christensen, G. Christiansen, S. Molin, S. and S. Kjelleberg, 1998. Two separate regulatory systems participate in control of swarming motility of Serratia liquefaciens MG1. J. Bacteriol., 180: 742-745.

57. Liu, X.Y. and P. Matsumura, 1994. The FlhD/FlhC complex, a transcriptional activator of the Escherichia coli flagellar class II operons. J. Bacteriol., 176: 7345-7351.

58. Macnab, R.M., 1992. Genetics and biogenesis of bacterial flagella. Ann. Rev. Genet., 26: 131-158.

59. Pruss, B.M. and P. Matsumura, 1996. A regulator of the flagellar regulon of Escherichia coli, flhD, also affects cell division. J. Bacteriol., 178: 668674.

60. Parachuri, D.K. and R.M. Harshey, 1987. Flagellar variation in Serratia marcescens is associated with color variation. http://www.ncbi.nlm.nih.gov/entrez/query.fcgi?cmd=Retrieve\& $\mathrm{db}=$ PubMed\&dopt=Abstract\&list_uids $=3539927$ $\mathrm{J}$. Bacteriol., 169: 61-65.

61. Al Mamun, A.A., A. Tominaga and M. Enomoto, 1996. Detection and characterization of the flagellar master operon in the four Shigella subgroups. J. Bacteriol., 178: 3722-3726.

62. Fuqua, C., S.C. Winans and E.P. Greenberg., 1996. Census and consensus in bacterial ecosystems: the LuxRLuxI family of quorum-sensing transcriptional regulators. Annu. Rev. Microbiol., 50: 727-751.
63. Khan, E.A., L.S. Wafelman, J.A. Garcia-Prats and L.H. Taber, 1997. Serratia marcescens pneumonia, empyema and pneumatocele in a preterm neonate. Pediatr. Infect. Dis. J., 16: 1003-1005.

64. Harshey, R.M., 1994. Bees aren't the only ones: Swarming in gram-negative bacteria. Mol. Microbiol., 13: 389-394.

65. Kutsukake, K., 1997. Autogenous and global control of the flagellar master operon, flhD, in Salmonella typhimurium. Mol. Gen. Genet., 254: 440- 448.

66. Harshey, R.M., G. Estepa and H. Yanagi, 1989. Cloning and nucleotide sequence of a flagellincoding gene (hag) from Serratia marcescens 274. Gene, 79: 1-8.

67. Lai, H.C., M.J. Lai, S. Lin-Chao, K.T. Luh and S.W. Ho, 1997. Population cell differentiation of Serratia marcescens on agar surface and in broth culture. Chung Hua Ming Kuo Wei Sheng Wu Chi Mien I Hsueh Tsa Chih, 30: 242-254.

68. Hurng, Liua, J. et al., 2000. Role of flhDC in the Expression of the Nuclease Gene nucA, Cell Division and Flagellar Synthesis in Serratia marcescens. J. Biomed. Sci., 7: 475-483.

69. Chen, Y.C., G.L. Shipley, T.K. Ball and M.J. Benedik, 1992. Regulatory mutants and transcriptional control of the Serratia marcescens extracellular nuclease gene. Mol. Microbiol., 6: 643-651.

70. Ball, T.K., C.R. Wasmuth, S.C. Braunagel and M.J. Benedik, 1990. Expression of Serratia marcescens extracellular proteins requires recA. J. Bacteriol., 172: 342-349.

71. Sunaga, S. et al., 2004. Identification and Characterization of the $p s w P$ gene required for the parallel production of prodigiosin and serrawettin W1 in Serratia marcescens. Microbiol. Immunol., 48: 723-728.

72. Haddix, P.L. and T.F. Werner, 2000. Spectrophotometric Assay of Gene Expression: Serratia marcescens Pigmentation. Bioscene, Vol. 26: 4.

73. Williams, P., N.J. Bainton, S. Swift, S.R. Chhabra, M.K. Winson, Stewart, G. S. A. B., Salmond, G. P. C. and B.W. Bycroft., 1992. Small-moleculemediated density-dependent control of gene expression in prokaryotes: bioluminescence and the biosynthesis of carbapenem antibiotics. FEMS Microbiol. Let., 100: 161-168.

74. Haddix, P.L., E.T. Paulsen and T.F. Werner, 2000. Measurement of mutation to antibiotic resistance: Ampicillin resistance in Serratia marcescens. Bioscene: J. College Biology Teaching, 26: 17-21.

75. Kerr, J.F.R., C.M. Winterford and B.V. Harmon, 1994. Apoptosis. Its significance in cancer and cancer therapy. Cancer, 73: $2013 \pm 2026$. 
76. Wickremasinghe, R.G. and A.V. Hoffbrand, 1999. Biochemical and genetic control of apoptosis: relevance to normal hematopoiesis and hematological malignancies. Blood, 93: $3587 \pm$ 3600 .

77. Reed, J.C., 1999. Mechanisms of apoptosis avoidance in cancer. Curr. Opin. Oncol., 11: $68 \pm 75$.

78 Zychlinsky, A. and P. Santonetti, 1997. Apoptosis in bacterial pathogenesis. J. Clin. Invest., 100: S63 \pm S65.

79. Chen, Y. and A. Zychlinsky, 1994. Apoptosis induced by bacterial pathogens. Microb. Pathogenesis, 17: $203 \pm 212$.

80. Chen, L.M., K. Kaniga and J.E. Galan, 1996. Salmonella spp. Are cytotoxic for cultured macrophages. Mol. Microbiol., 21: $1101 \pm 1115$.

81. Lindgren, S.W., I. Stojikovic and F. Heffron, 1996. Macrophage killing is an essential virulence mechanism of Salmonella typhimurium. Proc. Natl. Acad. Sci. U.S.A., 93: $4197 \pm 4201$.

82. Monack, D.M., B. Raupach, A.E. Hromockyj and S. Falkow, 1996. Salmonella typhimurium invasion induces apoptosis in infected macrophages. Proc. Natl. Acad. Sci. U.S.A., 93: $9833 \pm 9838$.

83. Kato, S., M. Muro, S. Akifusa, N. Hanada, I. Semba, T. Fuji, Y. Kowashi and T. Nishihara, 1995. Evidence for apoptosis of murine macrophages by Actinobacillus actinomycetemcomitans infection. Infect. Immun. 63: $3914 \pm 3919$.

84. Hildebrand, A., M. Pohl and S. Bhakdi, 1991. Staphylococcus aureus a-toxin: dual mechanisms of binding to target cells. J. Biol. Chem., 266: $17195 \pm 17200$.

85. Insupova, D.V. et al., 1977. Prodigiosin as a possible inhibitor of Serratia marcescens nuclease. Mikrobiologiia, 46: 245-51.

86. Kochi, S.K. and R.J. Collier, 1993. DNA fragmentation and cytolysis in U937 cells treated with diphtheria toxin or other inhibitors of protein synthesis. Exp. Cell Res., 208: $296 \pm 302$.

87. Morimoto, H. and B. Bonavida, 1992. Diphtheria toxin and pseudomonas a toxin mediated apoptosis. J. Immunol., 149: $2089 \pm 2094$.

88. Yoshida, J., S. Takamura and M.M. Nishio, 1998. Characterization of a streptococcal antitumor glycoprotein (SAGP). Life Sci., 62: $1043 \pm 1053$.

89. Arab, S., J. Rutka and C. Lingwood, 1999. Verotoxin induces apoptosis and the complete, rapid, long-term elimination of human astrocytoma xenografts in nude mice. Oncol. Res., 11: $33 \pm 39$.

90. Cameron, R. and G. Feuer, 2000. Mollecular cellular and tissue reactions of apoptosis and their modulation by drugs. In: Handbook of experimental pharmacology, Vol. 142, Ed. Cameron, R.G. and Feuer, G., Germany, Springer.
91. Montaner, B. et al., 2000. Prodigiosin from the supernatant of Serratia marcescens induces apoptosis in haematopoietic cancer cell lines. British J. Pharmacol., 131: $585 \pm 593$.

92. Han, S.B., H.M. Kim, Y.H. Kim, C.W. Lee, E.S. Jang, K.H. Son, S.U. Kim and Y.K. Kim, 1998. Tcell specific immunosuppression by prodigiosin isolated from Serratia marcescens. Intl. J.

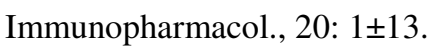

93. Mortellaro, A., S. Songia, P. Gnocchi, M. Ferrari, C. Fornasiero and R. D'Alessio et al., 1999. New immunosuppressive drug PNU156804 blocks IL-2 dependent proliferation and NF-kB and AP-1 activation. J. Immunol., 162: 7102-7109.

94. Wang, C., J.J. Cusack, R. Liu and A.J. Baldwin, 1999. Control of inducible chemoresistance: enhanced anti-tumor therapy through increased apoptosis by inhibition of NF-kB. Nature Med., 5: $412 \pm 417$.

95. Kawauchi, K., K. Shibutani, H. Yagisawa, H. Kamata, S. Nakatsuji and H. Anzai, et al., 1997. A possible immunosuppressant, cycloprodigiosin hydrochloride, obtained from Pseudoalteromonas denitrificans. Biochem. Biophys. Res. Commun., 237: 543-547.

96. Azuma, T., N. Watanabe, H. Yagisawa, H. Hirata, M. Iwamura and Y. Kobayashi, 2000. Induction of apoptosis of activated murine splenic $\mathrm{T}$ cells by cycloprodigiosin hydrochloride, a novel immunosuppressant. Immunopharmacology, 46: 29-37.

77. Yamamoto, C., H. Takemoto, K. Kuno, D. Yamamoto, A. Tsubura, K. Kamata et al., 1999. Cycloprodigiosin hydrochloride, a new $\mathrm{H}+/ \mathrm{Cl}$ À symporter, induces apoptosis in human and rat hepatocellular cancer cell lines in vitro and inhibits the growth of hepatocellular carcinoma xenografts in nude mice. Hepatology, 30: 894-902.

98. Tsuji, R.F., J. Magae, M. Jamashita, K. Nagai and M. Yamasaki, 1992. Immunomodulating properties of prodigiosin 25-C, an antibiotic which preferentially suppresses of cytotoxic T cells. J. Antibiot., 45: $1295 \pm 1302$.

99. Gottlieb, R.A., J. Nordberg, E. Skowronski and B.M. Babior, 1996. Apoptosis induced in Jurkat cells by several agents is preceded by intracellular acidification. Proc. Natl. Acad. Sci. U.S.A., 93: $654 \pm 658$.

100.Brown, J.M. and B.G. Wouters, 1999. Apoptosis, p53 and tumor cell sensitivity to anticancer agents. Cancer Res., 59: $1391 \pm 1399$.

101.Bunz, F., P.M. Hwang, C. Torrance, T. Waldman, Y. Zhang, L. Dillehay, J. Williams, C. Lengauer, K.W. Kinzler and B. Vogelstein, 1999. Disruption of p53 in human cancer cells alters the responses to therapeutic agents. J. Clin. Invest., 104: $263 \pm 269$. 
102.Montaner, B., S. Navarro, M. Piqué, M. Vilaseca, M. Martinell and E. Giralt et al., 2000. Prodigiosin from supernatant of Serratia marcescens induces apoptosis in haematopoietic cancer cell lines. Br. J. Pharmacol., 131: 583-593.

103.Campa`s, C. et al., 2003. Prodigiosin induces apoptosis of $\mathrm{B}$ and $\mathrm{T}$ cells from $\mathrm{B}$-cell chronic lymphocytic leukemia. Leukemia, 17: 746-750.

104.Montaner, B. and R. Pérez-Tomás, 1998. Prodigiosin-induced apoptosis in human colon cancer cells. Life Sci. 2001; 68: 2025-2036. 5 Kipps TJ. Chronic lymphocytic leukaemia. Curr. Opin. Hematol., 5: 244-253.

105. Yamamoto, D., Y. Uemura, K. Tanaka, K. Nakai,

C. Yamamoto and H. Takemoto et al., 2000. Cycloprodigiosin hydrochloride, $\mathrm{H}+/ \mathrm{Cl}$ À symporter, induces apoptosis and differentiation in HL-60 cells. Int. J. Cancer, 88: 121-128.

106.Jungdon, B., M. Hyunsoo, O. Kyeong-Keun, K. Chang-Ho, S.L. Dae, W.K. Seung and H. Suk-In, 2001. A novel bioreactor with an internal adsorbentfor intergrated fermentation and recovery of prodigiosin like pigment produced from Serratia sp.

http://www.ncbi.nlm.nih.gov/entrez/query.fcgi?cmd=Retrieve\& $\mathrm{db}=$ PubMed\&dopt $=$ Abstract\&list_uids=10.1023/A:1010573427 080 Biotechnol. Letts., 23: 1315-1319.

107.Han S.B., S.H. Park, Y.J. Jeon, Y.K. Kim, H.M. Kim and K.H. Yang, 2001. Prodigiosin blocks T cell activation by inhibiting interleukin $2 \mathrm{Ra}$ expression and delays progression of autoimmune diabetes and collagen- induced arthritis. Pharmacol. Exp. Ther., 299: 415-425.
108.Songia, S., A. Mortellaro, S. Taverna, C. Fornasiero, E.A. Scheiber and E. Erba et al., 1997. Characterization of the new immunosuppressive drug undecylprodigiosin in human lymphocytes. J. Immunol., 158: 3987-3995.

109.Bellosillo, B., N. Villamor, D. Colomer, G. Pons, E. Montserrat and J. Gil, 1999. In vitro evaluation of fludarabine in combination with cyclophosphamide and/or mitoxantrone in B-cell chronic lymphocytic leukemia. Blood, 94: 2836-2843.

110.Consoli, U., I. El-Tounsi, A. Sandoval, V. Snell, H.D. Kleine and W. Brown, 1998. Differential induction of apoptosis by fludarabine monophosphate in leukemic $\mathrm{B}$ and normal $\mathrm{T}$ cells in chronic lymphocytic leukemia. Blood, 91: 17421748.

111. Melvin, M.S., J.T. Tomlinson, G.R. Saluta, G.L. Kucera, N. Lindquist and R.A. Manderville, 2000. Double-strand DNA cleavage by copperprodigiosin. J. Am. Chem. Soc., 122: 6333-6334. Prodigiosin induces apoptosis of B-CLL cells C Campa`s et al 750.

112.Vogelstein, B., D. Lane and A.J. Levine, 2000. Surfing the p53 network. Nature, 408: 307-310.

113.Kalesperis, G.S, 1975. Toxigenic studies with the antibiotic pigments from Serratia marcescens, Can. J. Microbiol., 21: 213-20.

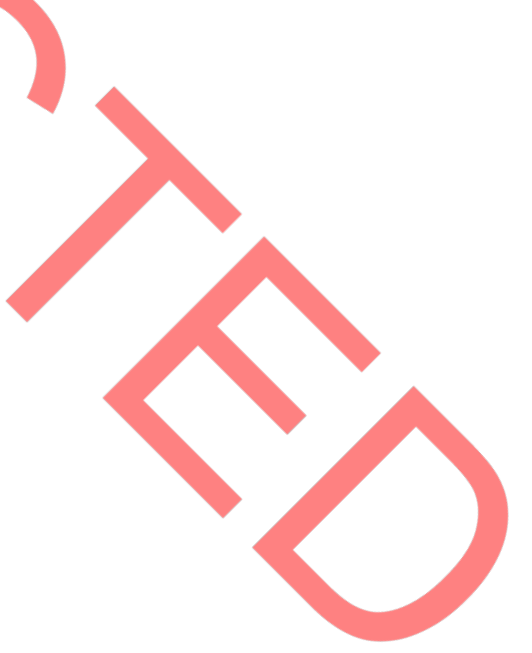

